\title{
Streptacidiphilus oryzae sp. nov., an actinomycete isolated from rice-field soil in Thailand
}

Correspondence

Michael Goodfellow

m.goodfellow@ncl.ac.uk

\author{
Liming Wang, ${ }^{1,2}$ Ying Huang, ${ }^{1}$ Zhiheng Liu, ${ }^{1}$ Michael Goodfellow ${ }^{2}$ \\ and Carlos Rodríguez ${ }^{2} \dagger$
}

\author{
${ }^{1}$ State Key Laboratory of Microbial Resources, Institute of Microbiology, Chinese Academy of \\ Sciences, Beijing 100080, People's Republic of China \\ ${ }^{2}$ Division of Biology, King George VI Building, University of Newcastle, Newcastle upon Tyne \\ NE1 7RU, UK
}

\begin{abstract}
The taxonomic position of ten acidophilic actinomycetes isolated from an acidic rice-field soil was established using a polyphasic approach. 16S rRNA gene sequences determined for the isolates were aligned with corresponding sequences of representatives of the genera Kitasatospora, Streptacidiphilus and Streptomyces and phylogenetic trees were inferred using four tree-making algorithms. The isolates had identical sequences and formed a distinct branch at the periphery of the Streptacidiphilus 16S rRNA gene tree. The chemotaxonomic and morphological properties of representative isolates were consistent with their assignment to the genus Streptacidiphilus. The isolates shared nearly identical phenotypic profiles that readily distinguished them from representatives of the established species of Streptacidiphilus. It is evident from the genotypic and phenotypic data that the isolates form a homogeneous group that corresponds to a novel species in the genus Streptacidiphilus. The name proposed for this new taxon is Streptacidiphilus oryzae sp. nov.; the type strain is strain $\mathrm{TH}_{4}{ }^{\top}$ (=CGMCC $4.2012^{\top}=$ JCM $13271^{\top}$ ).
\end{abstract}

Acidophilic actinomycetes with streptomycete-like properties are common in terrestrial habitats with low $\mathrm{pH}$ values, notably in acid forest soils (Williams et al., 1971; Goodfellow \& Dawson, 1978; Seong et al., 1993). Acidophilic strains grow at $\mathrm{pH}$ values between about $3 \cdot 5$ and $6 \cdot 5$, with an optimal $\mathrm{pH}$ around $4 \cdot 5$; their neutrotolerant counterparts grow at $\mathrm{pH}$ values between $4 \cdot 5$ and $7 \cdot 5$, with optimal growth between pH $5 \cdot 0$ and $5 \cdot 5$ (Williams et al., 1971; Kim et al., 2004; Xu et al., 2006). It is important to clarify the taxonomy of acidophilic sporoactinomycetes, as they are involved in the turnover of fungal biomass in acid litters and soils (Williams \& Robinson, 1981) and are a source of antifungal antibiotics (Williams \& Khan, 1974) and acid-stable enzymes (Williams \& Robinson, 1981).

Kim et al. (2003) proposed the genus Streptacidiphilus for a group of strictly acidophilic strains. They recognized three species, Streptacidiphilus albus, the type species, Streptacidiphilus carbonis and Streptacidiphilus neutrinimicus. A further species, Streptacidiphilus jiangxiensis Huang et al. 2004, has been added to the genus. Representatives of these taxa form

†Present address: Departamento de Cencias Biológicas, Facultad de Recursos, Escuela Superior Politécnica de Chimborazo, PO Box 06-01104, Correo Central Riobamba, Ecuador.

The GenBank/EMBL/DDBJ accession number for the 16S rRNA gene sequence of Streptacidiphilus oryzae $\mathrm{TH}_{4} \mathrm{~T}^{\top}$ is DQ208700. a distinct 16S rRNA gene clade within the evolutionary radiation encompassed by the family Streptomycetaceae Waksman and Henrici 1943 emend. Kim et al. 2003, a taxon that also contains the genera Kitasatospora and Streptomyces. Representatives of these genera have many properties in common but can be distinguished from one another using a range of genotypic and phenotypic properties (Groth et al., 2003, 2004; Kim et al., 2003). In a continuation of studies on the biodiversity of acidophilic sporoactinomycetes, a group of strains were isolated which grew well at $\mathrm{pH} 3 \cdot 5$. These organisms were the subject of a polyphasic study that showed that they formed a novel species within the genus Streptacidiphilus.

Strains TH31, TH35, TH37, TH49 ${ }^{\mathrm{T}}$, TH51, TH54, TH63, TH69, TH74 and TH78 were isolated on starch-caseinnitrate agar (Küster \& Williams, 1964) adjusted to $\mathrm{pH} 4 \cdot 5$ using a citric acid/disodium hydrogen phosphate buffer (McIlvaine, 1921) and supplemented with the antifungal antibiotics cycloheximide and nystatin (each at $50 \mu \mathrm{g}$ $\mathrm{ml}^{-1}$ ). The isolation plates had been inoculated with a soil suspension prepared using a modification of the dispersion and differential centrifugation procedure (Hopkins et al., 1991), as described by Sembiring et al. (2000), and incubated at $28{ }^{\circ} \mathrm{C}$ for 14 days. The soil sample had been collected from a rice field in Nontaburi Province, Thailand. The isolates were maintained on modified Bennett's agar 
plates (Jones, 1949), adjusted to $\mathrm{pH} 5 \cdot 0$, for short-term storage, and as suspensions of mycelial fragments and spores in $20 \%(\mathrm{v} / \mathrm{v})$ glycerol at $-20{ }^{\circ} \mathrm{C}$ for long-term maintenance.

The phylogenetic relationships of the isolates were determined by $16 \mathrm{~S}$ rRNA gene sequence analysis using biomass grown in shake flasks of modified Bennett's broth (Jones, 1949), adjusted to $\mathrm{pH} 5 \cdot 0$, and incubated for 5 days at $28^{\circ} \mathrm{C}$. The biomass preparations were washed twice in Tris-EDTA buffer $(0.03 \mathrm{M}$ Tris, $0.1 \mathrm{M}$ EDTA; $\mathrm{pH} 8.0)$ and stored at $-20{ }^{\circ} \mathrm{C}$. Genomic DNA preparations were prepared and used as templates for PCR amplification and sequencing according to the procedure of Kim et al. (1998). The resultant almost complete $16 \mathrm{~S}$ rRNA gene sequences were aligned manually, using the pairwise alignment option and $16 \mathrm{~S}$ rRNA secondary structural information held in the PHYDIT program (available at http://plaza.snu.ac.kr/ jchun/phydit/), against corresponding sequences of representatives of the genera Kitasatospora, Streptacidiphilus and Streptomyces retrieved from the GenBank/EMBL/DDBJ databases.

Phylogenetic trees were inferred using the least-squares (Fitch \& Margoliash, 1967), maximum-likelihood (Felsenstein, 1981), maximum-parsimony (Fitch, 1971) and neighbourjoining (Saitou \& Nei, 1987) tree-making algorithms from the PHYLIP suite of programs (Felsenstein, 1993). Evolutionary distance matrices for the least-squares and neighbour-joining methods were generated after Jukes \& Cantor (1969). The unrooted tree topologies were evaluated by using a bootstrap analysis (Felsenstein, 1985) of the neighbour-joining dataset based on 1000 resamplings using the TREECON program (Van de Peer \& De Wachter, 1994).

The ten isolates had identical 16S rRNA gene sequences. Phylogenetic analyses showed that they formed a distinct lineage at the periphery of the evolutionary radiation encompassed by representatives of the genus Streptacidiphilus (Fig. 1). This association was supported by the results from the four tree-making algorithms and by a bootstrap value of $71 \%$ in the neighbour-joining analysis. The isolates shared 16S rRNA gene similarities of between 95.6 and $96.7 \%$ with representatives of Streptacidiphilus species with validly published names, values that corresponded to between 46 and 62 nucleotide differences at 1407 locations.

Chemotaxonomic studies were carried out on four representative strains, namely isolates $\mathrm{T} 31, \mathrm{TH} 49^{\mathrm{T}}, \mathrm{TH} 54$ and TH74, to determine whether they had properties consistent with their assignment to the genus Streptacidiphilus. Biomass needed to determine the chemical properties of the strains was grown in shake flasks of modified Bennett's broth, as described above except that cells for quantitative fatty acid analyses were prepared on tryptic soy agar plates as described by Zhang et al. (2003). Harvested biomass was

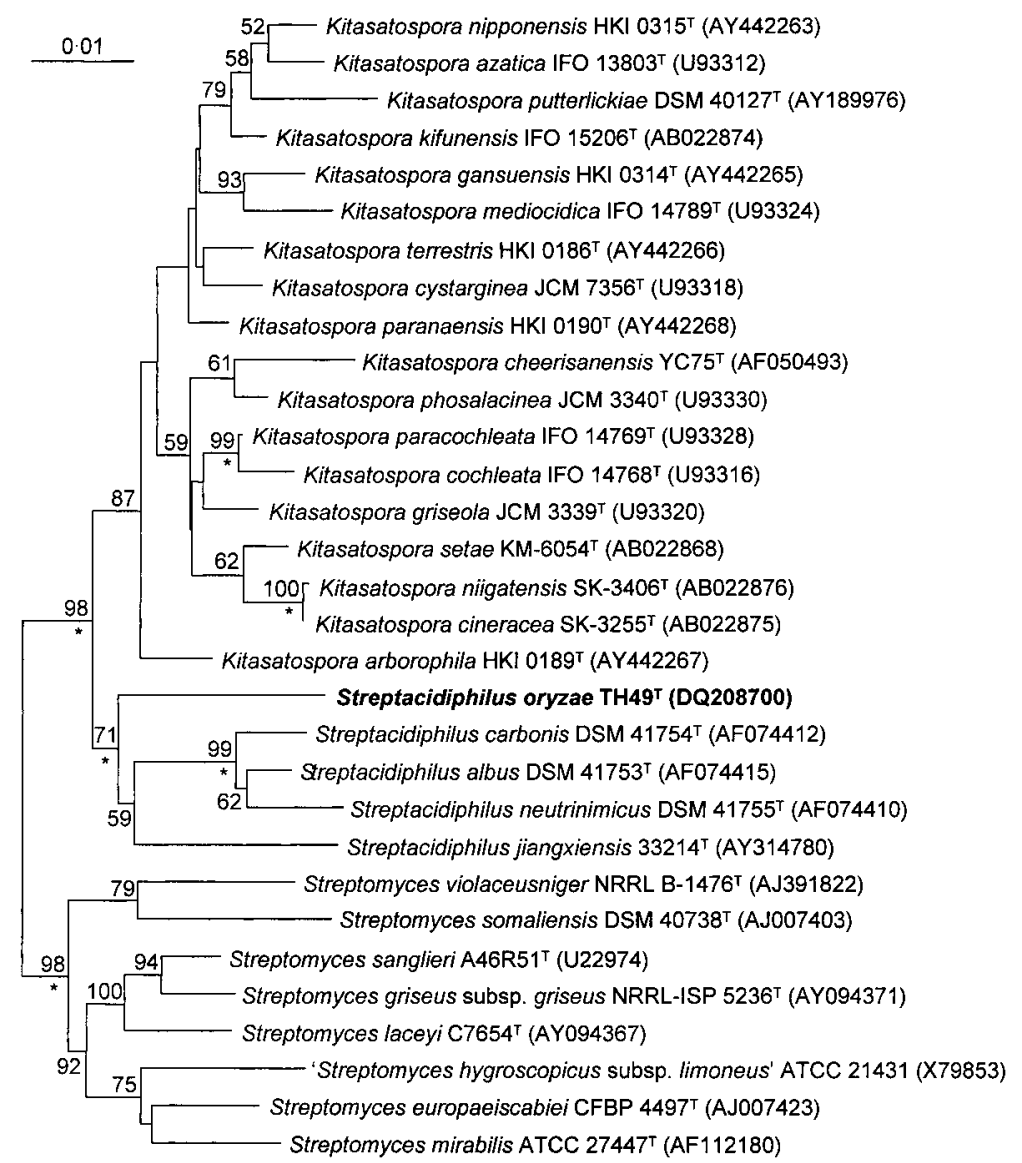

Fig. 1. Neighbour-joining tree (Saitou \& Nei, 1987), based on nearly complete $16 \mathrm{~S}$ rRNA gene sequences, showing the position of Streptacidiphilus oryzae sp. nov. $\mathrm{TH}_{4} 9^{\top}$ in the phylogenetic tree of the Streptomycetaceae. Asterisks indicate branches that were recovered using the least-squares (Fitch \& Margoliash, 1967), maximum-likelihood (Felsenstein, 1981) and maximum-parsimony (Fitch, 1971) tree-making algorithms. Numbers at nodes are percentage bootstrap values based on 1000 resampled datasets; only values above $50 \%$ are given. Bar, 0.01 nucleotide substitutions per nucleotide position. 
washed twice with distilled water and freeze-dried. Standard procedures were used for the extraction and analysis of fatty acids (MIDI System; http://www.midi-inc.com), diagnostic isomers of diaminopimelic acids (Lechevalier \& Lechevalier, 1980; Hasegawa et al., 1983), isoprenoid quinones (Collins, 1985; Wu et al., 1989), polar lipids (Minnikin et al., 1984) and sugars (Lechevalier \& Lechevalier, 1980).

The diamino acid of the peptidoglycan was LL-diaminopimelic acid, although traces of the meso-isomer were detected. The representative strains contained hexahydrogenated and octahydrogenated menaquinones with nine isoprene units as the predominant isoprenologues, contained diphosphatidylglycerol, phosphatidylethanolamine, phosphatidylinositol and phosphatidylinositol mannosides as major polar lipids (phospholipid type II sensu Lechevalier et al., 1977) and were shown to be rich in saturated straightchain and iso- and anteiso-branched fatty acids (fatty acid type 2c sensu Kroppenstedt, 1985). All of these attributes are typical of members of the genus Streptacidiphilus (Kim et al., 2003; Huang et al., 2004). However, whole-organism hydrolysates of the strains contained galactose, glucose, mannose and ribose, not the combination of galactose and rhamnose reported for representatives of the Streptacidiphilus species with validly published names (Kim et al., 2003; Huang et al., 2004).

The ten strains were grown on modified Bennett's agar (Jones, 1949), inorganic salts-starch agar (ISP 4 medium; Shirling \& Gottlieb, 1966) and oatmeal agar (ISP 3 medium; Küster, 1959) plates, adjusted to $\mathrm{pH} 5 \cdot 0$, at $28^{\circ} \mathrm{C}$ for 14 days. The incubated plates were examined by eye to determine aerial spore-mass colour, substrate mycelial pigmentation and the colour of any diffusible pigments; colours were recorded using the National Bureau of Standards Color Name Charts (Kelly, 1958; National Bureau of Standards, 1964). The undisturbed arrangement of hyphae and sporechain morphology were observed on oatmeal agar plates using the cover-slip technique of Kawato \& Shinobu (1959). Spore-chain arrangement and spore-surface ornamentation were examined on dehydrated, gold-coated specimens of strains TH35, TH49 ${ }^{\mathrm{T}}$, TH54 and TH63 by using a FEI

Table 1. Phenotypic properties that separate the new isolates from representatives of established Streptacidiphilus species

Strains: 1, isolates TH31, TH35, TH37, TH49 ${ }^{\mathrm{T}}$, TH54, TH63, TH69, TH74 and TH78; 2, Streptacidiphilus albus JL13, JL81, JL83 ${ }^{\mathrm{T}}$, JL85,

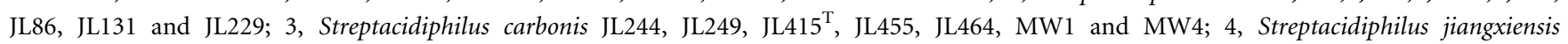
22202, 32214 and $33214^{\mathrm{T}}$; 5, Streptacidiphilus neutrinimicus JL135, JL206 ${ }^{\mathrm{T}}$, JL215, JL218 and JL246. Data in columns 2-5 were taken from Huang et al. (2004).

\begin{tabular}{|c|c|c|c|c|c|}
\hline Characteristic & 1 & 2 & 3 & 4 & 5 \\
\hline \multicolumn{6}{|c|}{ Growth on acidified oatmeal agar } \\
\hline Aerial spore mass colour & Greyish white & White & White & White to greyish white & White \\
\hline Colour of diffusible pigment & Golden brown & None & None & None & None \\
\hline \multicolumn{6}{|l|}{ Degradation of: } \\
\hline Tweens 40 and 60 & + & + & - & - & - \\
\hline \multicolumn{6}{|c|}{ Growth on sole carbon sources at $1 \%(\mathrm{w} / \mathrm{v})$} \\
\hline D-Gluconic acid & + & - & - & - & - \\
\hline D-Glucosamine hydrochloride & + & + & - & + & + \\
\hline Glycerol & + & + & + & - & + \\
\hline myo-Inositol & + & - & + & + & - \\
\hline L-Arginine & - & + & + & - & + \\
\hline L-Aspartic acid & - & + & + & - & - \\
\hline Sodium oxalate & - & - & - & + & - \\
\hline \multicolumn{6}{|c|}{$\begin{array}{l}\text { Growth on sole carbon and nitrogen source at } \\
0 \cdot 1 \%(w / v)\end{array}$} \\
\hline L-Isoleucine & + & - & - & + & - \\
\hline \multicolumn{6}{|l|}{ Growth at: } \\
\hline $30^{\circ} \mathrm{C}$ & + & - & + & + & - \\
\hline $35^{\circ} \mathrm{C}$ & + & - & - & + & - \\
\hline $\mathrm{pH} 6 \cdot 0$ & + & + & + & + & - \\
\hline
\end{tabular}


Quanta scanning electron microscope. The strains tested formed extensively branched substrate mycelia carrying abundant aerial hyphae that differentiated into long straight to flexuous chains of smooth-surfaced spores, these properties being consistent with their assignment to the genus Streptacidiphilus.

The spore suspensions used to inoculate a broad range of phenotypic tests were prepared from 14-day-old acidified oatmeal agar plates by following the procedure described by Hopwood et al. (1985). The strains were examined for their ability to grow on oatmeal agar adjusted to $\mathrm{pH} 3 \cdot 0,3 \cdot 5,4 \cdot 5$, $5 \cdot 5,6 \cdot 5$ and $7 \cdot 5$ using the citric acid/disodium hydrogen phosphate buffer system (McIlvaine, 1921); the tests were carried out in Replidishes (Sterilin) 14 days after the inoculation of compartments with the appropriate spore suspension $(5 \mu \mathrm{l})$. The remaining phenotypic tests were carried out using established procedures (Williams et al., 1983; Seong et al., 1993), albeit with acidified media. All of the isolates grew well at $\mathrm{pH}$ values from $3 \cdot 5$ to $6 \cdot 5$; only strains $\mathrm{TH} 31$, TH74 and TH78 failed to grow at $\mathrm{pH} 3 \cdot 0$. The isolates also grew at 28 and $37^{\circ} \mathrm{C}$, but not at 10 or $45^{\circ} \mathrm{C}$. The isolates shared many properties, as shown in Table 1 and in the species description. It is evident from Table 1 that the isolates can be separated from representatives of Streptacidiphilus with validly published names by means of a combination of phenotypic tests.

It is apparent from the genotypic and phenotypic data that the isolates belong to a distinct homogeneous taxon within the genus Streptacidiphilus. It is proposed that these organisms be assigned to a novel Streptacidiphilus species. The name proposed for this taxon is Streptacidiphilus oryzae sp. nov.

\section{Description of Streptacidiphilus oryzae sp. nov.}

Streptacidiphilus oryzae (o.ry.za'e. L. gen. n. oryzae of rice, denoting the isolation of the strains from a rice field).

Aerobic, Gram-positive, non-acid-alcohol-fast actinomycetes that form a brown substrate mycelium and abundant greyish-white aerial hyphae on acidified modified Bennett's, inorganic salts-starch, oatmeal and yeast extract-malt extract agar. Aerial hyphae differentiate into long flexuous chains of spores $(0.7 \times 1.0 \mu \mathrm{m})$ with smooth surfaces. Golden brown diffusible pigments are formed on acidified modified Bennett's, oatmeal and yeast extract-malt extract agar, but not on inorganic salts-starch agar. Growth occurs at $\mathrm{pH} 3 \cdot 0-6 \cdot 5$ and at $28-37^{\circ} \mathrm{C}$. Degrades adenine, casein, starch and uric acid, but not elastin, guanine, hypoxanthine, Tween 80, L-tyrosine, xanthine or xylan. Nitrate is reduced. Aesculin, allantoin and urea are not hydrolysed. L-Arabinose, D-arabitol, D-cellobiose, D-fructose, D-galactose, D-glucose, glycogen, D-lactose, D-mannitol, D-mannose, D-raffinose, L-rhamnose, D-salicin (weak), sucrose (weak), D-trehalose, D-xylose (each at $1 \%, \mathrm{w} / \mathrm{v}$ ) and L-alanine, DL- $\alpha$-aminobutryric acid, 2-aminoethanol, L-histidine (weak), L-isoleucine (weak), L-phenylalanine, sodium fumarate (weak), sodium pyruvate (weak), L-threonine and L-valine (each at $0 \cdot 1 \%$, $\mathrm{w} / \mathrm{v}$ ) are used as sole carbon sources for energy and growth, but adonitol, dextran, methyl $\alpha$-D-glucoside, ethanol, glycine (each at $1 \%, \mathrm{w} / \mathrm{v}$ ), adipic acid, L-arginine, L-aspartic acid, L-cysteine, potassium nitrate and sodium oxalate (each at $0 \cdot 1 \%, \mathrm{w} / \mathrm{v}$ ) are not. L-Alanine, 2-aminoethanol, L-aspartic acid, L-isoleucine (weak) and L-phenylalanine (each at $0 \cdot 1 \%, \mathrm{w} / \mathrm{v}$ ) are used as sole carbon and nitrogen sources. Growth occurs in the presence $\left(\mu \mathrm{g} \mathrm{ml}^{-1}\right)$ of amoxicillin (16), fusidic acid (16), gentamicin sulphate (16, weak), lincomycin hydrochloride (16) and penicillin $\mathrm{G}$ (8, weak) but not in the presence of amikacin (32), amoxicillin (32), ampicillin $(16,32)$, cephalexin $(16,32)$, cephaloridine hydrochloride $(32,64)$, clindamycin hydrochloride (4), doxycycline hydrochloride (16), gentamicin sulphate (16), neomycin sulphate $(16,32)$, novobiocin $(8)$, penicillin G (16), streptomycin sulphate $(8,16)$, tetracycline hydrochloride $(16,32)$ or lead acetate $(100)$. Weak growth occurs in the presence of $5 \%(\mathrm{w} / \mathrm{v}) \mathrm{NaCl}$.

The type strain, TH49 ${ }^{\mathrm{T}}\left(=\mathrm{CGMCC} 4.2012^{\mathrm{T}}=\mathrm{JCM} 13271^{\mathrm{T}}\right)$, was isolated from a rice-field soil sample collected in Nontaburi Province, Thailand.

\section{Acknowledgements}

This study was supported through the Royal Society-Chinese Academy of Sciences Exchange Scheme (grant number Q814) and by the National Natural Science Foundation of China (grant numbers 30270003 and 30370002). C. R. gratefully acknowledges receipt of a studentship from the Ecuadorian FUNDACYT (Foundation for Science and Technology) and an Overseas Research Studentship Award.

\section{References}

Collins, M. D. (1985). Isoprenoid quinone analysis in classification and identification. In Chemical Methods in Bacterial Systematics, pp. 267-289. Edited by M. Goodfellow \& D. E. Minnikin. London: Academic Press.

Felsenstein, J. (1981). Evolutionary trees from DNA sequences: a maximum likelihood approach. J Mol Evol 17, 368-376.

Felsenstein, J. (1985). Confidence limits on phylogenies: an approach using the bootstrap. Evolution 39, 783-791.

Felsenstein, J. (1993). PHYLIP (phylogeny inference package), version 3.5c. Distributed by the author. Department of Genome Sciences, University of Washington, Seattle, USA.

Fitch, W. M. (1971). Toward defining the course of evolution: minimum change for a specific tree topology. Syst Zool 20, 406-416.

Fitch, W. M. \& Margoliash, E. (1967). Construction of phylogenetic trees: a method based on mutation distances as estimated from cytochrome $c$ sequences is of general applicability. Science 155, 279-284.

Goodfellow, M. \& Dawson, D. (1978). Qualitative and quantitative studies of bacteria colonizing Picea sitchensis litter. Soil Biol Biochem 10, 303-307.

Groth, I., Schütze, B., Boettcher, T., Pullen, C. B., Rodriguez, C., Leistner, E. \& Goodfellow, M. (2003). Kitasatospora putterlickiae sp. nov., isolated from rhizosphere soil, transfer of Streptomyces kifunensis to the genus Kitasatospora as Kitasatospora kifunensis comb. nov., and emended description of Streptomyces aureofaciens Duggar 1948. Int J Syst Evol Microbiol 53, 2033-2040. 
Groth, I., Rodriguez, C., Schütze, B., Schmitz, P., Leistner, E. \& Goodfellow, M. (2004). Five novel Kitasatospora species from soil: Kitasatospora arboriphila sp. nov., K. gansuensis sp. nov., K. nipponensis sp. nov., K. paranensis sp. nov. and $K$. terrestris sp. nov. Int J Syst Evol Microbiol 54, 2121-2129.

Hasegawa, T., Takizawa, M. \& Tanida, S. (1983). A rapid analysis for chemical grouping of aerobic actinomycetes. J Gen Appl Microbiol 29, 319-322.

Hopkins, D. W., MacNaughton, S. J. \& O'Donnell, A. G. (1991). A dispersal and differential centrifugation technique for representatively sampling microorganisms from soil. Soil Biol Biochem 23, 217-225.

Hopwood, D. A., Bibb, M. J., Chater, K. F., Kieser, T. C. J., Kieser, H. M., Lydiate, D. J., Smith, C. P., Ward, J. M. \& Schrempf, H. (1985). Genetic Manipulation of Streptomyces. A Laboratory Manual. Norwich: The John Innes Foundation.

Huang, Y., Cui, Q., Wang, L., Rodriguez, C., Quintana, E., Goodfellow, M. \& Liu, Z. (2004). Streptacidiphilus jiangxiensis sp. nov., a novel actinomycete isolated from acidic rhizosphere soil in China. Antonie van Leeuwenhoek 86, 159-165.

Jones, K. L. (1949). Fresh isolates of actinomycetes in which the presence of sporogenous aerial mycelia is a fluctuating characteristic. $J$ Bacteriol 57, 141-145.

Jukes, T. H. \& Cantor, C. R. (1969). Evolution of protein molecules. In Mammalian Protein Metabolism, vol. 3, pp. 21-213. Edited by H. N. Munro. New York: Academic Press.

Kawato, M. \& Shinobu, R. (1959). On Streptomyces herbaricolor sp. nov., supplement: a single technique for microscopical observation. Mem Osaka Unit Lib Arts Educ B Nat Sci 8, 114-119 (in Japanese).

Kelly, K. L. (1958). Centroid notations for the revised ISCC-NBS color name blocks. J Res Nat Bur Standards U S A 61, 427.

Kim, S. B., Falconer, C., Williams, E. \& Goodfellow, M. (1998). Streptomyces thermocarboxydovorans sp. nov. and Streptomyces thermocarboxydus sp. nov., two moderately thermophilic carboxydotrophic species from soil. Int J Syst Bacteriol 48, 59-68.

Kim, S. B., Lonsdale, J., Seong, C.-N. \& Goodfellow, M. (2003). Streptacidiphilus gen. nov., acidophilic actinomycetes with wall chemotype I and emendation of the family Streptomycetaceae (Waksman and Henrici $1943^{\mathrm{AL}}$ ) emend. Rainey et al. 1997. Antonie van Leeuwenhoek 83, 107-116.

Kim, S. B., Seong, C. N., Jeon, S. J., Bae, K. S. \& Goodfellow, M. (2004). Taxonomic study of neutrotolerant acidophilic actinomycetes isolated from soil and description of Streptomyces yeochonensis sp. nov. Int J Syst Evol Microbiol 54, 211-214.

Kroppenstedt, R. M. (1985). Fatty acid and menaquinone analysis of actinomycetes and related organisms. In Chemical Methods in Bacterial Systematics, pp. 173-199. Edited by M. Goodfellow \& D. E. Minnikin. London: Academic Press.

Küster, E. (1959). Outline of a comparative study of criteria used in characterization of the actinomycetes. Int Bull Bacteriol Nomencl Taxon 9, 97-104.

Küster, E. \& Williams, S. T. (1964). Selection media for isolation of streptomycetes. Nature 202, 928-929.

Lechevalier, M. P. \& Lechevalier, H. A. (1980). The chemotaxonomy of actinomycetes. In Actinomycete Taxonomy (Special Publication 6), pp. 277-284. Edited by A. Dietz \& D. W. Thayer. Arlington, VA: Society for Industrial Microbiology.

Lechevalier, M. P., De Bièvre, C. \& Lechevalier, H. A. (1977). Chemotaxonomy of aerobic actinomycetes: phospholipid composition. Biochem Syst Evol 5, 249-260.

Mcllvaine, T. C. (1921). A buffer solution for colorimetric comparison. J Biol Chem 49, 183-186.

Minnikin, D. E., O'Donnell, A. G., Goodfellow, M., Alderson, G., Athalye, M., Schaal, A. \& Parlett, J. H. (1984). An integrated procedure for the extraction of isoprenoid quinones and polar lipids. J Microbiol Methods 2, 233-241.

National Bureau of Standards (1964). ISCC-NBS Color Manual Charts Illustrated with Centroid Colors. Supplement to NBS Circular 553. Washington, DC: US Government Printing Office.

Saitou, N. \& Nei, M. (1987). The neighbor-joining method: a new method for reconstructing phylogenetic trees. Mol Biol Evol 4, 406-425.

Sembiring, L., Ward, A. C. \& Goodfellow, M. (2000). Selective isolation and characterisation of members of the Streptomyces violaceusniger clade associated with the roots of Paraserianthes falcataria. Antonie van Leeuwenhoek 78, 353-366.

Seong, C. N., Goodfellow, M., Ward, A. C. \& Hah, Y. C. (1993). Numerical classification of acidiphilic actinomycetes isolated from acid soil in Korea. Kor J Microbiol 31, 355-363.

Shirling, E. B. \& Gottlieb, D. (1966). Methods for characterization of Streptomyces species. Int J Syst Bacteriol 16, 313-340.

Van de Peer, Y. \& de Wachter, R. (1994). TREECON for windows: a software package for the construction and drawing of evolutionary trees for the Microsoft Windows environment. Comput Appl Biosci 10, 569-570.

Waksman, S. A. \& Henrici, A. T. (1943). The nomenclature and classification of the actinomycetes. J Bacteriol 46, 337-341.

Williams, S. T. \& Khan, M. R. (1974). Antibiotics - a soil microbiologist's viewpoint. Postepy Hig Med Dosw 28, 395-408.

Williams, S. T. \& Robinson, C. S. (1981). The role of streptomycetes in decomposition of chitin in acidic soils. J Gen Microbiol 127, 55-63.

Williams, S. T., Davies, F. L., Mayfield, C. I. \& Khan, M. R. (1971). Studies on the ecology of actinomycetes in soil. II. The $\mathrm{pH}$ requirements of streptomycetes from two acid soils. Soil Biol Biochem 3, 187-195.

Williams, S. T., Goodfellow, M., Alderson, G., Wellington, E. M. H., Sneath, P. H. A. \& Sackin, M. J. (1983). Numerical classification of Streptomyces and related genera. J Gen Microbiol 129, 1743-1813.

Wu, C., Lu, X., Qin, M., Wang, Y. \& Ruan, J. (1989). Analysis of menaquinone compound in microbial cells by HPLC. Microbiology [English translation of Microbiology (Beijing)]16, 176-178.

Xu, C., Wang, L., Cui, Q., Huang, Y., Liu, Z., Zheng, G. \& Goodfellow, M. (2006). Neutrotolerant acidophilic Streptomyces species isolated from acidic soils in China: Streptomyces guanduensis sp. nov., Streptomyces paucisporeus sp. nov., Streptomyces rubidus sp. nov. and Streptomyces yanglinensis sp. nov. Int J Syst Evol Microbiol 56, 1109-1115.

Zhang, J., Liu, Z. \& Goodfellow, M. (2003). Nocardia cashijiensis sp. nov., a novel soil actinomycete. Int J Syst Evol Microbiol 53, 999-1004. 